\title{
Klasifikasi Status Kinerja Bank yang Terdaftar di BEI dengan Pendekatan Winsorized Modified One-Step M-Estimator
}

\author{
Milani Destriana, Nurul Gusriani, Iin Irianingsih \\ Departemen Matematika FMIPA unpad, \\ milani1228@gmail.com, gusriani99@gmail.com iin.irianingsih@gmail.com
}

\begin{abstract}
Abstrak
Penilaian kinerja suatu bank dengan analisis laporan keuangan tidaklah efisien bagi pihak pengawas (BI, masyarakat atau investor), karena analisis laporan keuangan hanya dapat menilai bank secara perseorangan. Oleh karena itu, perlu adanya klasifikasi status kinerja bank yang dapat menilai bank termasuk berstatus kinerja baik atau tidak secara bersamaan. Data yang digunakan untuk klasifikasi adalah data laporan keuangan setiap bank yang terdaftar di BEI. Penilaian secara bersamaan memungkinkan munculnya data ekstrim (outlier), karena ada perbedaan kemampuan operasional antara bank ternama dan tidak. Metode yang digunakan untuk klasifikasi status kinerja bank adalah analisis diskriminan linear. Analisis diskriminan harus memenuhi asumsi kenormalan (normalitas) dan kesamaan matriks varians-kovarians (homoskedastisitas), namun metode ini sangat sensitif terhadap data yang mengandung outlier sehingga tidak memenuhi asumsi. Analisis diskriminan linear robust dengan pendekatan winsorized modified one-step Mestimator merupakan metode yang dapat mengatasi data outlier dan tidak terpenuhinya asumsi. Hasil yang diperoleh adalah dua buah fungsi diskriminan liner robust, dimana semua variabel bebas mempunyai pengaruh positif yang dapat meningkatkan skor diskriminan. Kedua fungsi digunakan untuk klasifikasi status kinerja bank yang terdaftar di BEI dengan ketepatan sebesar 65,28\%. Berdasarkan perhitungan presss $\mathrm{Q}$ fungsi diskriminan robust yang terbentuk memiliki hasil yang akurat dan stabil.

Kata kunci: Analisis diskriminan linear robust, Normalitas, Homoskedastisitas, outlier, winsorized modified one-step M-estimator.
\end{abstract}

2000 Mathematics Subject Classification: 47N30

Received: 2018-09-03, accepted: 2019-01-08 
136 Authors, JMI Vol 14 No 2, Oktober 2018, pp. 135-142,doi:10.24198/jmi.v14.n2.2018.135-142

\begin{abstract}
Assessment of the performance of a bank with financial statement analysis is not efficient for the supervisory (BI, community or investor), because the analysis of financial statements can only assess banks individually. Therefore, it is necessary to classify the performance status of banks that can assess banks simultaneously. The data used for classification is the financial report data of each bank listed on the IDX. Simultaneous assessment can bring out extreme data (outliers), because there are differences in operational capabilities between reputable banks and not. The method used for classification of bank performance status is linear discriminant analysis. Discriminant analysis must fill normal assumptions (normality) and similarities in the variance-covariance matrix (homoscedasticity), but this method is very sensitive to data containing outliers so that they do not meet assumptions. Robust linear discriminant analysis using the winsorized modified one-step M-estimator approach is a method that can overcome data outliers and assumptions are not fulfilled. The results obtained are two robust linear discriminant functions, where all independent variables have a positive influence that can increase the discriminant score. Both functions are used to classify the performance status of banks listed on the IDX with an opportunity of errors of 34,72

Keywords :Robust Linear Discriminant Analysis, Normality, Homoscedasticity, Robust, outlier, winsorized modified one-step M-estimator.
\end{abstract}

\title{
1. Pendahuluan
}

Pasal 29 Undang-Undang No. 10 tahun 1998 menyatakan bahwa mengingat bank bekerja dengan dana dari masyarakat yang disimpan pada bank atas dasar kepercayaan, setiap bank perlu terus menjaga kesehatannya dan memelihara kepercayaan masyarakat padanya [1]. Upaya suatu bank untuk menjaga kesehatannya dilakukan dengan menilai atau memprediksi kinerja bank tersebut dengan menggunakan analisis laporan keuangan. Pada dasarnya, analisis laporan keuangan hanya mampu menilai kinerja pada satu bank saja, sehingga bank tidak dapat membandingkan posisi dengan bank lainnya. Selain itu, bagi pihak pengawas (Bank Indonesia, masyarakat, dan investor) cara ini tidak cukup efektif. Oleh karena itu, perlu adanya prediksi status kinerja untuk setiap bank yang dapat dijadikan sebagai bahan evaluasi oleh bank untuk terus meningkatkan kinerjanya. Hal tersebut juga dapat dijadikan acuan masyarakat untuk menaruh kepercayaan kepada bank yang tepat serta dijadikan acuan untuk pihak pengawas dalam menilai kinerja suatu bank. Memprediksi status kinerja bank sama dengan menentukan klasifikasi individu ke dalam suatu kelompok. Salah satu metode yang digunakan untuk mengklasifikasi individu ke dalam salah satu kelompok dari dua kelompok atau lebih adalah analisis diskriminan [1]. Analisis diskriminan yang sering digunakan adalah analisis diskriminan linear. Pada analisis diskriminan linear harus memenuhi dua asumsi, yaitu variabel bebas berdistribusi normal multivariat, matriks varians-kovarians dari kedua kelompok data yang diamati homogen. Analisis diskriminan klasik (linear dan kuadrartik) tidak dapat bekerja dengan baik jika data yang dianalisis mengandung outlier [8]. [5] juga menuliskan bahwa analisis diskriminan sangat sensitif terhadap ketidaknormalan dan/atau heteroskedastisitas. Adanya outlier, ketidaknormalan dan heteroskedastisitas berpengaruh pada keakuratan hasil pengklasifikasian analisis diskriminan. Agar analisis diskriminan tetap optimal meskipun dalam kondisi tersebut, maka diperlukan suatu penaksir yang robust. Analisis diskriminan yang menggunakan penaksir robust selanjutnya disebut sebagai analisis diskriminan robust. Sharipah, et. al (2016) memperkenalkan metode baru yang dapat mengatasi keduanya untuk mengklasifikasi 
kebangkrutan bank yang ada di Malaysia. Pada penelitian ini, penulis mengklasifikasi status kinerja bank yang terdaftar di Bursa Efek Indonesia (BEI) menggunakan analisis diskriminan linear robust dengan pendekatan winsorized modified one-step M-estimator (WMOM) [11] dengan bantuan aplikasi Maple 15. Metode ini akan membentuk fungsi diskriminan linear robust yang digunakan sebagai dasar klasifikasi status kinerja bank.

\section{Metode Penelitian}

Untuk menganalisis data dengan analisis diskriminan linear haruslah dilakukan pengujian asumsi terhadap kenormalan, kesamaan matriks varians-kovarians dan keberadaan outlier. Hal ini dilakukan untuk menentukan apakah metode yang akan digunakan adalah analisis diskriminan linear klasik atau robust.

2.1. Uji Kenormalan Multivariat. Menurut Johnson dan Wichern (2002), pada beberapa analisis di multivariat, biasanya diasumsikan bahwa variabel independen harus berdistribusi normal. Ada beberapa metode untuk menguji kenormalan multivariat salah satunya adalah mencari nilai jarak mahalanobis (jarak kuadrat) untuk setiap observasi. Jarak mahalanobis dihitung dengan:

$$
d_{i(R)}^{2}=\left(X^{(R)}-\bar{X}^{(R)}\right)^{T} S^{-1}\left(X^{(R)}-\bar{X}^{(R)}\right)
$$

Kenormalan multivariat diperoleh dengan menghitung nilai korelasi Pearson untuk melihat hubungan linear antara $d_{z}^{2}$ dengan $\chi_{p\left(g_{z}\right)} \cdot \chi_{p\left(g_{z}\right)}$ adalah nilai Chi-Kuadrat dengan $g_{z}=\frac{(z-0,5)}{n}$ dan derajat kebebasan $(d k)=p$, dimana

$d_{i(R)}^{2} \quad:$ nilai jarak mahalanobis untuk setiap observasi ke- $i$ dari kelompok ke- $R, i=1,2, \ldots, n^{(R)}$

$\bar{X}^{(R)} \quad$ : matriks vektor rata-rata variabel yang ke- $k$ dari kelompok ke- $R(i \times p)$

$S_{g a b} \quad$ : matriks varians-kovarians dalam kelompok gabungan (seluruh $\left.R\right)(p \times p)$

$S_{g a b}^{-1} \quad$ : kebalikan (inverse) matriks varians-kovarians $S_{g a b}(p \times p)$.

Jika terdapat hubungan linear antara jarak mahalanobis dengan Chi-Kuadrat maka terpenuhinya asumsi kenormalan

2.2. Uji Kesamaan Matriks Varians-Kovarians. Kesamaan matriks varians-kovarians merupakan salah satu asumsi yang harus dipenuhi pada analisis diskriminan linear. Untuk menguji kesamaan matriks varians-kovarians $\left(\sum\right)$ antar kelompok, digunakan hipotesis: [10]

$H_{0}: \sum_{1}=\sum_{2}=\cdots=\sum_{r}$ (matriks varians-kovarians untuk semua kelompok sama)

$H_{1}$ : Sedikitnya ada satu kelompok yang matriks varians-kovariansnya berbeda

Uji kesamaan matriks varians-kovarians dihitung dengan statistik BoxM yaitu:

$$
\ln M=\frac{1}{2} \sum_{R=1}^{r} V^{(R)} \ln \left|S^{(R)}\right|-\frac{1}{2}\left(\sum_{R=1}^{r} V^{(R)}\right) \ln \left|S_{g a b}\right|
$$

$\ln M$ dapat didekati dengan distribusi $F$ dengan aturan sebagai berikut: Jika $C_{2}>C_{1}^{2}$, maka $F_{h}=-2 u_{1} \ln M$

Jika $C_{2}<C_{1}^{2}$ maka $F_{h}=-\frac{2 a_{2} u_{1} \ln M}{a_{1}\left(1+2 u_{2} \ln M\right)}$

dengan nilai $a_{1}, a_{2}, u_{1}, u_{2}, C_{1}, C_{2}$ sebagai berikut:

$$
\begin{gathered}
C_{1}=\left(\sum_{R=1}^{r} \frac{1}{\left(V^{(R))^{2}}\right.}-\frac{1}{\left(\sum_{R=1}^{r}\left(V^{\left.(R))^{2}\right)^{2}}\right)\left(\frac{\left(2 p^{2}+3 p-1\right)}{6(p+1)(r-1)}\right)\right.}\right. \\
C_{2}=\left(\frac{(p-1)(p+2}{6(r-1)}\right)\left(\sum_{R=1}^{r} \frac{1}{\left(V^{(R))^{2}}-\frac{1}{\left(\sum_{R=1}^{r}\left(V^{(R))^{2}}\right)^{2}\right.}\right)}\right. \\
a_{1}=\frac{1}{2}(r-1) p(p+1)
\end{gathered}
$$




$$
\begin{gathered}
a_{2}=\frac{a_{1}+2}{\left|C_{2}-C_{1}^{2}\right|} \\
u_{1}=\frac{1-C_{1}-a_{1} / a_{2}}{a_{1}} \\
u_{2}=\frac{1-C_{1}+2 / a_{2}}{a_{2}}
\end{gathered}
$$

Apabila $F_{h}<F_{\left(a_{1}, a_{2}, \alpha\right)}$ maka $H_{0}$ diterima dan dapat dinyatakan bahwa semua kelompok mempunyai matriks varians-kovarians yang sama. Sebaliknya bila $F_{h}>F_{\left(a_{1}, a_{2}, \alpha\right)}$ maka $H_{0}$ ditolak.

2.3. Pendeteksian outlier. Menurut Gimnez et al. (2012), pendekatan klasik untuk mendeteksi adanya outlier adalah dengan menghitung jarak mahalanobis dari masing-masing pengamatan. Jarak mahalanobis didefinisikan pada persamaan (1). Jika nilai $d_{i(R)}^{2}>\chi_{p(1-\alpha)}$ maka data observasi ke- $i$ pada kelompok $(R)$ merupakan outlier.

2.4. Analisis Diskriminan Linear. Menurut Johnson dan Wichern (2002), analisis diskriminan merupakan salah satu metode dalam analisis multivariat dan termasuk dalam teknik dependensi (hubungan antarvariabel dimana sudah dapat dibedakan mana variabel dependen dan mana variabel independen). Analisis diskriminan digunakan untuk mengklasifikasikan individu ke dalam salah satu dari dua kelompok atau lebih, dimana variabel respon berupa data kualitatif dan variabel penjelas berupa data kuantitatif. Analisis diskriminan yang sering digunakan adalah analisis diskriminan linear. Ada dua asumsi utama yang harus dipenuhi pada analisis diskriminan linear ini, yaitu variabel penjelas harus berdistribusi normal dan matriks varians-kovarians variabel penjelas berukuran $p \times p$ pada kedua kelompok harus sama. Fungsi diskriminan didefinisikan sebagai berikut:

$$
L^{(R)}(X)=c_{1}^{(R)} X_{1}+c_{2}^{(R)} X_{2}+c_{3}^{(R)} X_{3}+\cdots+c_{k}^{(R)} X_{k}+\cdots+c_{p}^{(R)} X_{p}+C_{0}^{(R)}
$$

dimana:

$$
L^{(R)}(X)=\left(\bar{X}^{(R)}\right)^{T} S_{g a b}^{-1} X-\frac{1}{2}\left(\bar{X}^{(R)}\right)^{T} S_{g a b}^{-1} \bar{X}+\ln \left(\frac{n^{(R)}}{n}\right)
$$

2.5. Analisis Diskriminan Linear Robust dengan winsorized modified one-step Mestimator. Analisis diskriminan linear robust adalah analisis diskriminan yang memiliki fungsi diskriminan berupa linear dan asumsi-asumsi pada analisis diskriminan tidak terpenuhi dan/atau terdapat outlier pada data. Metode winsorized modified one-step M-estimator digunakan untuk membentuk penaksir rata-rata baru sebagai salah satu cara memperkuat fungsi diskriminan. Bahkan dalam proses winsorizing, secara tidak langsung metode ini mengatasi outlier.

Wilcox dan Keselman (2003) mengenalkan modified one-step M-estimator dengan nilai $k=2.24$ yang efisien untuk $n \leq 100$ yaitu sebagai berikut:

$$
\hat{\mu}=\frac{\sum_{t=t_{1+1}}^{n-t_{2}} x_{t}}{n-t_{1}-t_{2}}
$$

\footnotetext{
dimana

$\hat{\mu} \quad:$ modified one-step M-estimator

$t_{1}$ : banyaknya pengamatan yang memenuhi $x_{i}-\operatorname{Median}\left(x_{i}\right)<-2,24 \cdot M A D$ Berdasarkan

$t_{2}$ : banyaknya pengamatan yang memenuhi $x_{i}-\operatorname{Median}\left(x_{i}\right)>2,24 \cdot M A D$

modified one-step M-estimator pada persamaan (11), Haddad et al (2013) membuat alternatif lain yaitu dengan membangun winsorized sample dengan aturan sebagai berikut:
} 


$$
w_{t k}^{(R)}=\left\{\begin{array}{l}
x_{\left(t_{1}+1\right) k}^{(R)}, x_{t k}^{(R)} \leq x_{\left(t_{1}+1\right) k}^{(R)} \\
x_{t k}^{(R)}, x_{\left(t_{1}+1\right) k}^{(R)}<x_{t k}^{(R)}<x_{\left(n-t_{2}\right) k}^{(R)} \\
x_{\left(n-t_{2}\right) k}^{(R)}, \geq x_{\left(n-t_{2}\right) k}^{(R)}
\end{array}\right.
$$

$w_{t k}^{(R)} \quad$ : observasi baru ke- $t$ untuk variabel ke- $k$ pada kelompok ke $-R$ (winsorized sample)

$t \quad$ : nomor urut dariyang telah diurutkan dari nilai terkecil hingga terbesar dengan $t=1,2, \cdots n$

$t_{1} \quad$ : banyaknya pengamatan yang memenuhi $x_{i}-\operatorname{Median}\left(x_{i}\right)<-2,24 \cdot M A D$

$t_{2} \quad$ : banyaknya pengamatan yang memenuhi $x_{i}-\operatorname{Median}\left(x_{i}\right)>2,24 \cdot M A D$

Berdasarkan persamaan (12), terbentuk winsorized sample, sehingga perumusan winsorized modified one-step M-estimator

$$
\bar{w}_{i k}^{(R)}=\sum_{t=1}^{n^{(R)}} \frac{w_{t k}^{(R)}}{n^{(R)}}
$$

dimana,

$$
\begin{array}{ll}
\bar{w}_{i k}^{(R)} & : \text { penaksir rata-rata baru untuk variabel ke- } k \text { pada kelompok ke } R \\
w_{t k}^{(R)} & : \text { observasi baru ke- } t \text { untuk variabel ke- } k \text { pada kelompok ke } R \text { (winsorized sample) } \\
t & : \text { nomor urut dari } x_{i k}^{(R)} \text { yang telat diurutkan dari nilai terkecil hingga terbesar dengan } t=1,2, \cdots n
\end{array}
$$

\subsection{Evaluasi Hasil Analisis Diskriminan Linear.}

2.6.1. Apparent Error Rate (APER). Menurut Johnson and Wichern (2002), cara penting untuk menilai kinerja dari setiap prodesur klasifikasi adalah menghitung tingkat kesalahan atau probabilitas kesalahan klasifikasi. Metode untuk menghitung probabilitas kesalahan klasifikasi adalah Apparent Error Rate (APER) sebagai berikut:

$$
\text { Apparent Error Rate }=\frac{n^{(1)(2)}+n^{(2)(1)}}{n^{(1)}+n^{(2)}}
$$

dengan

$n^{(1)(2)}$ : banyaknya observasi yang kelompok sebenarnya 1 dan kelompok prediksinya 2

$n^{(2)(1)}$ : banyaknya observasi yang kelompok sebenarnya 2 dan kelompok prediksinya 1

$n^{(1)} \quad$ : banyaknya observasi pada kelompok satu

$n^{(1)} \quad$ : banyaknya observasi pada kelompok dua

2.6.2. Menilai Keakuratan Prediksi Keanggotaan Kelompok. Akurasi merupakan nilai yang diperhatikan untuk mendapatkan hasil klasifikasi yang terbaik. Jika nilai akurasi semakin besar maka semakin tepat hasil klasifikasinya. Menurut Hair, et al. (2006) statistik uji Presss Q membandingkan antara jumlah ketepatan klasifikasi dengan total pengamatan dan banyaknya kelompok.

dengan

$$
\operatorname{Presss} Q=\frac{[n-(q r)]^{2}}{n(r-1)}
$$

$n$ : jumlah observasi untuk seluruh kelompok

$q \quad$ : jumlah observasi yang diprediksi secara tepat, $q=n^{(1)(1)}+n^{(2)(2)}$

$r$ : banyaknya kelompok

Jika, Presss $\mathrm{Q}>\chi_{(\alpha, 1)}^{2}$ maka pengklasifikasian akurat dan fungsi diskriminan yang terbentuk stabil.

\section{Hasil dan Pembahasan}

Data yang digunakan adalah data sekunder mengenai laporan keuangan setiap bank yang terdaftar di Bursa Efek Indonesia (BEI) tahun 2016-2017, yang diperoleh dari web resmi BEI (www.idx.co.id). Variabel independen yang digunakan adalah kondisi keuangan bank yang tercatat dalam BEI berdasarkan pertumbuhan laba. Bank yang memiliki pertumbuhan laba 
menurun atau bernilai negatif diberikan kategori 1 sedangkan bank yang memiliki pertumbuhan laba naik atau bernilai positif diberikan kategori 2. Untuk variabel dependen yang digunakan adalah capital adequency ratio, net-performing loan, net profit margin, return on assets, net interest margin, biaya operasional terhadap pendapatan operasional, dan loan to deposits ratio.

3.1. Hasil Uji Kenormalan Multivariat. Nilai korelasi Pearson antara jarak mahalanobis dan chi-kuadrat adalah sebesar 0,90566. Nilai $r$ tabel dengan $\alpha=0,05$ dan $d k=34$ yaitu $r_{1}=0,329$. Oleh karena itu, keputusan uji adalah menolak $H_{0}$ karena $r_{h}>r_{t}$, artinya terdapat hubungan linear antara jarak mahalanobis dan nilai chi-kuadrat, dengan demikian asumsi kenormalan terpenuhi.

3.1.1. Hasil Uji Kesamaan Matriks Varians-Kovarians. Uji asumsi kesamaan matriks varianskovarians dilakukan karena asumsi kenormalan data terpenuhi. Hasil pengujian kesamaan matriks varians-kovarians dengan menggunakan Uji Boxs M pada persamaan (2) sampai dengan (8) dapat dilihat pada Tabel 1

TABel 1. Hasil Perhitungan Uji Kesamaan Matriks Varians-Kovarians

\begin{tabular}{|c|c|}
\hline Perhitungan Boxs M & Nilai \\
\hline $\ln M$ & $-73,1016$ \\
\hline$C_{1}$ & 0,0252 \\
\hline$C_{2}$ & 0,0923 \\
\hline$a_{1}$ & 28 \\
\hline$a_{2}$ & 327 \\
\hline$u_{1}$ & 0,0318 \\
\hline$u_{2}$ & 0,003 \\
\hline$F_{h}$ & 4,643 \\
\hline$F_{\left(a_{1}, a_{2}, \alpha\right)}$ & 1,511 \\
\hline
\end{tabular}

Berdasarkan Tabel 1 diperoleh nilai $\ln M$ yaitu $-73,1016$ dengan nilai $F_{h}=4,4643$. Nilai $F_{t}$ dengan alpha $=0,05, a_{1}=28$ dan $a_{2}=327$ adalah 1,51. Berdasarkan hipotesis: $H_{0}: \sum_{1}=\sum_{2}=\cdots=\sum_{r}$ (matriks varians-kovarians untuk semua kelompok sama)

$H_{1}$ : Sedikitnya ada satu kelompok yang matriks varians-kovariansya berbeda

sehingga keputusan uji adalah menolak $H_{0}$ karena $F_{h}=4,643$ dan $F_{t}=1,51$ sehingga $F_{h}>F_{t}$, artinya terdapat sedikitnya satu kelompok yang matriks varians-kovariansnya berbeda, atau dapat disebut matriks varians-kovarians bersifat heterogen, sehingga uji kesamaan matriks varians-kovarians tidak terpenuhi.

3.2. Analisis Diskriminan Linear Robust dengan Winsorized modified one step M-estimator. Vektor winsorized modified one-step M-estimator dengan menggunakan persamaan (13) diperoleh sebagai berikut:

$$
\begin{gathered}
\bar{w}^{(2)}=\left[\begin{array}{lllllll}
21,121 & 2,465 & 6,589 & 0,594 & 5,58 & 90,618 & 87,1
\end{array}\right] \\
\bar{w}^{(2)}=\left[\begin{array}{lllllll}
21,272 & 1,627 & 13,1732 & 1,296 & 5,3 & 84,456 & 87,114
\end{array}\right]
\end{gathered}
$$

Karena telah didapat vektor WMOM lalu didapat fungsi diskriminan pertama dan kedua yaitu: $L_{i}^{(2)}=-262,621+1,425 X_{i 1}+12,771 X_{i 2}+3,6965 X_{i 3}+0,06 X_{i 4}+1,674 X_{i 5}+3,258 X_{i 6}+1,6743 X_{i 7}$

$L_{i}^{(2)}=-262,621+1,406 X_{i 1}+11,073 X_{i 2}+3,71 X_{i 3}+0,0479 X_{i 4}+1,435 X_{i 5}+3,298 X_{i 6}+1,63 X_{i 7}$ 
Pada dua fungsi yang terbentuk dapat dinyatakan bahwa setiap variabel bebas memiliki pengaruh positif yang meningkatkan skor diskriminan.

3.3. Hasil Klasifikasi. Fungsi diskriminan yang telah terbentuk selanjutnya digunakan untuk memprediksi status kinerja bank di BEI dengan menggunakan data testing. Cara mengklasifikannya adalah dengan menghitung skor diskriminan pada setiap fungsi kelompok yaitu fungsi diskriminan satu dan fungsi diskriminan dua. Suatu observasi diklasifikasikan pada kelompok yang mempunyai skor diskriminan tertinggi. Setelah mengklasifikasi status kinerja bank termasuk ke dalam status baik atau buruk, selanjutnya menilai ketepatan klasifikasinya dengan membandingkan dengan kelompok sebenarnya. Setelah itu akan dilihat seberapa baik fungsi diskriminan linear robust mengklasifikasikan status kinerja bank dengan tepat. Hal ini dapat dilihat pada Tabel 2.

TABEL 2. Klasifikasi Kelompok

\begin{tabular}{cccc}
\hline Kelompok yang sebenarnya & Jumlah observasi pada setiap kelompok & \multicolumn{2}{c}{ Kelompok prediksi } \\
\hline & & 1 & 2 \\
1 & 34 & 12 & 22 \\
2 & 38 & 3 & 35 \\
\hline
\end{tabular}

Berdasarkan Tabel 2 didapat nilai APER sebesar 0,3472 atau 34,72\%, ini berarti hasil ketepatan klasifikasi sebesar $65,28 \%$. Selain itu, angka Presss Q didapatkan dengan persamaan (15) yaitu sebesar 6,722. Berdasarkan Tabel Chi Kuadrat, didapat $\chi_{(0,05 ; 1)}^{2}=3,84$ dengan $\alpha=0,05$ dan derajat kebebasan $d k=1$, karena Presss $Q>\chi_{(0,05 ; 1)}^{2}$ artinya pengklasifikasian dengan menggunakan analisis diskriminan linear robust akurat dan fungsi diskriminan linear robust yang terbentuk stabil.

\section{Simpulan}

Hasil dari penelitian ini dapat disimpulkan sebagai berikut:

(1) Analisis diskriminan linear robust dengan pendekatan winsorized modified one-step M-estimator pada data bank yang terdaftar di Bursa Efek Indonesia menghasilkan fungsi diskriminan linear robust pada persamaan (18) dan (19) yang digunakan untuk memprediksi baik-buruknya status kinerja bank. Berdasarkan uji Presss Q fungsi diskriminan linear robust yang telah terbentuk memiliki ketepatan klasifikasi yang akurat dan stabil.

2)

(2) terdaftar di Bursa Efek Indonesia, 15 diklasifikasikan mempunyai kinerja buruk (pertumbuhan laba negatif) sisanya yaitu 57 diklasifikasikan mempunyai kinerja baik (pertumbuhan laba positif) dengan ketepatan klasifikasi sebesar $65,28 \%$.

\section{DAFtar Pustaka}

[1] Bank Indonesia. 1998. UU No.10 tahun 1998, Tentang Perubahan Terhadap UU No. 7 tahun 1992, Jakarta

[2] Bursa Efek Indonesia. 2016. Laporan Keuangan. www.idx.co.id. Diakses pada hari Jumat, tanggal 13 April 2018.

[3] Bursa Efek Indonesia. 2017. Laporan Keuangan. www.idx.co.id. Diakses pada hari Jumat, tanggal 13 April 2018.

[4] Gimnez, E., Crespi, M., Garrido, S., and Gil, A.J., 2012, Multivariate outlier detection based on robust computation of Mahalanobis distances, International Journal of Applied Earth Observation and Geoinformation 16, 94-100

[5] Glele Kakai, R.M., Pelz, D., and Palm, R., 2010. The efficiency of the linear classification rule in multigroup discriminant analysis. Afr. J. Math. Comput.Sci. Res., 3: 019-025 
142 Authors, JMI Vol 14 No 2, Oktober 2018, pp. 135-142,doi:10.24198/jmi.v14.n2.2018.135-142

[6] Haddad, F. S., Yahaya, S. S. S., and Alfaro, J. L. 2013. Alternative hotelling's T2 charts using winsorized modified one-step M-estimator. Quality Reliability Eng. Int., 29: 583-593. DOI: 10.1002/qre.1407

[7] Hair. J. F., Black. W. C., Babin. B. J., Anderson R. E. 2006. Multivariate Data Analysis. Seventh Edition. Pearson Education Prentice Hall. Inc

[8] Hawkins, D.M, 1997, Identification of outliers, Chapman and Hall, New York

[9] Johnson, R.A. dan Wichern, D.W. 2002. Applied Multivariate Statistical Analysis. 5th Ed., Prentice Hall. New Jersey

[10] Rencher, A. C. 2002. Methods of Multivariate Analysis. Second Edition. Wiley-Interscience publication

[11] Sharipah, S.S.Y., Yai-Fung, L., Hazlina, A., Et al, 2016.Robust Linear Discriminant Analysis. Science Public (4): 312.316 DOI: 10.3844/jmssp.2016.312.316

[12] Wilcox, R.R. and Keselman, H. J., 2003. Repeated measures one-way ANOVA based on a modified one-step M-estimator. British Mathematical and Statistical Psychology, 56: 15-26. DOI: 10.1348/0007110033216453133 